\title{
Reductive Activation of Phenylalanine Hydroxylase and Its Effect on the Redox State of the Non-Heme Iron ${ }^{\dagger}$
}

\author{
D. E. Wallick, L. M. Bloom, Betty Jean Gaffney, and S. J. Benkovic*
}

ABSTRACT: Phenylalanine hydroxylase undergoes an obligatory prereduction step in order to become catalytically active as shown by stopped-flow kinetics and by measuring tyrosine formation at limiting 6-methyltetrahydropterin levels. This initial step requires oxygen and involves conversion of 6 methyltetrahydropterin directly to the quinonoid form with or without phenylalanine. The EPR spectrum of the resting enzyme $\left(g_{\text {eff }}=9.4-8.7,4.3\right.$ and $\left.g_{\text {eff }}=6.7,5.4\right)$ is consistent with two species possessing distinctively different ligand environments for the non-heme, high-spin $\mathrm{Fe}^{3+}$. The intensity of the $g_{\text {eff }} \simeq 4.3$ feature is inversely proportional to the specific activity of the enzyme, whereas the intensity of the $g_{\text {eff }} \simeq$ 6.7-5.4 region correlates with the activity of the enzyme. The

I n our attempts to understand the mechanism of action of phenylalanine hydroxylase (PAH) ${ }^{1}$ from rat liver, we (Gottschall et al., 1982) recently confirmed and extended an earlier observation by Fisher et al. (1972) that a tightly bound non-heme iron was necessary for the activity of the enzyme. We demonstrated that (1) the correct stoichiometry is one atom per subunit, (2) the enzymatic activity is proportional to the iron content, and (3) the iron can be removed from the enzyme and restored with nearly complete recovery of initial activity. In this paper we corroborate and expand the independent discovery (Marota \& Shiman, 1984) that PAH is initially reduced to the catalytically active enzyme by the concomitant oxidation of 6-methyltetrahydropterin $\left(6 \mathrm{MPH}_{4}\right)$ directly to the quinonoid form in a stoichiometric reaction requiring oxygen but without the formation of reduced forms of oxygen such as superoxide and hydrogen peroxide, or of tyrosine. In this paper we (1) propose a two-step kinetic sequence for PAH activation and its catalytic turnover based on stopped-flow kinetic and complimentary product data, (2) define by EPR that the resting state of the activatable enzyme is associated with signals observed at $g_{\text {eff }}=6.7$ and 5.4 consistent with high-spin $\mathrm{Fe}^{3+}(S=5 / 2)$, (3) show that the additional EPR signal observed at $g_{\text {eff }}=4.3$ is associated with a form of the enzyme that is incapable of turnover, and (4) link the prereduction step to the conversion of PAH from an $\mathrm{Fe}^{3+}$ to an $\mathrm{Fe}^{2+}$ state. Finally, we demonstrate that dithionite can substitute for $6 \mathrm{MPH}_{4}$ in the prereduction step and that the addition of one electron/subunit is sufficient to impart tightly coupled turnover.

Experimental Procedures

\section{Materials}

Doubly distilled deionized water was used throughout. All reagents were of the highest grade commercially available.

\footnotetext{
${ }^{\dagger}$ From the Department of Chemistry, The Pennsylvania State University, University Park, Pennsylvania 16802 (D.E.W. L.M.B., and S.J.B.), and the Department of Chemistry, The John Hopkins University, Baltimore, Maryland 21218 (B.J.G.). Received July 7, 1983. This work was supported in part by National Science Foundation Grant PCM8103670 (S.J.B.) and by National Institutes of Health Grant GM28070 (B.J.G.)
}

latter features are lost upon addition of phenylalanine under anaerobic or aerobic conditions. In the presence of $o$ phenanthroline, the operation of the prereduction step results in nearly quantitative trapping of the iron in an $\mathrm{Fe}^{2+}$ redox state. Dithionite can substitute for 6-methyltetrahydropterin in an anaerobic prereduction step, generating a catalytically active phenylalanine hydroxylase containing $\mathrm{Fe}^{2+}$ that functions aerobically to produce tyrosine from added 6-methyltetrahydropterin in a $1 / 1$ stoichiometry. Reductive titration of the hydroxylase by dithionite is consistent with the addition of one electron/subunit for coupled turnover. The implications of these findings for the mechanism of action of this enzyme are briefly discussed.

2-Amino-4-hydroxy-6-methyltetrahydropterin $\left(6 \mathrm{MPH}_{4}\right)$ was prepared by catalytic hydrogenation over $10 \% \mathrm{Pd} / \mathrm{C}$ of 2 amino-4-hydroxy-6-methylpterin (Storm et al., 1971). Tris, L-phenylalanine, 2,6-dichloroindophenol, dithiothreitol, bovine serum albumin, sperm whale skeletal muscle myoglobin, FAD, EDTA, and human transferrin (98\%) were purchased from Sigma. L-Tyrosine, from Nutritional Biochemicals Corp., was recrystallized from water. Ferrous ammonium sulfate was purchased from Baker. Beef liver catalase was purchased either from Boehringer Mannheim (as a crystalline suspension in water, stabilized with $0.01 \%$ alkylbenzyldimethylammonium chloride) or from Sigma (as a $2 \times$ crystallized suspension in water containing $0.1 \%$ thymol).

\section{Methods}

All assay solutions were air saturated, unless otherwise indicated. UV spectra were recorded on either a Cary 118 or Cary 219 spectrophotometer. Kinetic assays were carried out on a Gilford 240 or 252 instrument. Fluorescence spectra were measured with a Perkin-Elmer MPF 44A instrument. $\mathrm{pH}$ measurements were made with a Radiometer 22 instrument equipped with a Model PHA $630 \mathrm{~Pa}$ scale expander and a Radiometer GK-2302C electrode. Stopped-flow spectrophotometric experiments were carried out with a Durrum D-110 system.

Preparation of Phenylalanine Hydroxylase. PAH was purified from the livers of retired male breeder rats of the Wistar strain through step D of the method of Shiman et al. (1979), with the following modifications. Enzyme was eluted from the DE-52 ion-exchange column using equilibration buffer containing $0.3 \mathrm{M}$ potassium chloride instead of a potassium chloride gradient. Glycerin was omitted from both the DE-52 equilibration and elution buffers. Iron(II)-activated PAH was prepared by the method of Shiman \& Jefferson

\footnotetext{
1 Abbreviations: $\mathrm{PAH}$, phenylalanine hydroxylase; $\mathrm{NaDodSO}_{4}$, sodium dodecyl sulfate; $6 \mathrm{MPH}_{4}, 6$-methyltetrahydropterin; 4a-OH$6 \mathrm{MPH}_{4}$, the 4a-hydroxy adduct of $6 \mathrm{MPH}_{4}$; Tris, tris(hydroxymethyl)aminomethane; EPR, electron paramagnetic resonance spectroscopy; EDTA, ethylenediaminetetraacetic acid; FAD, flavin adenine dinucleotide.
} 
(1982), as adapted to the above purification by Gottschall et al. (1982). All experiments reported herein were conducted with iron(II)-activated PAH. Enzyme purity was determined to be $>95 \%$ by $\mathrm{NaDodSO}_{4}-8.75 \%$ polyacrylamide gel electrophoresis, performed according to the method of Laemmli (1970). Protein was measured by the Peterson modification of the Lowry procedure (Peterson, 1977) using bovine serum albumin as a protein standard. Proteins were corrected for overestimation according to Shiman (1980). The iron content of PAH was measured by means of a wet ashing method (Van De Bogart \& Beinert, 1967; Gottschall et al., 1982). Myoglobin from sperm whale skeletal muscle was used as the standard (Hapner et al., 1968). The PAH samples used in this work contained from 0.7 to $1.0 \mathrm{Fe} / 50000$-dalton PAH subunit. The designation "total PAH" refers to the concentration of protein obtained directly from the above purification, while "PAH ${ }_{o x}$ " or "PAH ${ }_{\text {red }}$ " refers to the concentration of enzyme containing ferric or ferrous iron. Enzyme concentrations designated as " $\mathrm{PAH}_{2 \mathrm{ct}}$ " are calculated (Shiman, 1980) by dividing the specific activity of the PAH sample by the specific activity of pure, fully active PAH, taken to be 14.4 units/mg (Shiman \& Jefferson, 1982), and normalizing the total enzyme subunit concentration by this ratio.

Enzyme Activity Assays. Phenylalanine hydroxylase was assayed at $25^{\circ} \mathrm{C}$ unless stated otherwise by either direct measurement of the rate of formation of oxidized cofactor (Ayling et al., 1973) (assay 1), measurement of the rate of tyrosine formation by following the change in absorbance at $275 \mathrm{~nm}$ (Shiman et al., 1979) (assay 2), or measurement of tyrosine formation from the fluorescence of the nitrosonaphthol derivative (Waalkes \& Udenfriend, 1957) (assay 3).

Spectrophotometric Examination of Pre-Steady-State Lag. The pre-steady-state lag in the formation of $4 \mathrm{a}-\mathrm{OH}-6 \mathrm{MPH}_{4}$ (Lazarus et al., 1981) was examined by stopped-flow spectrophotometry. $6 \mathrm{MPH}_{4}$, in $100 \mathrm{mM}$ potassium phosphate buffer at $\mathrm{pH} 6.8$, with catalase present, was mixed in the stopped-flow spectrophotometer with phenylalanine-activated PAH (Shiman \& Gray, 1980; Shiman, 1980) also in $100 \mathrm{mM}$ potassium phosphate buffer at $\mathrm{pH}$ 6.8. Upon mixing, the reactant concentrations were as follows: $100 \mathrm{mM}$ potassium phosphate, $\mathrm{pH} 6.8,50 \mu \mathrm{g} / \mathrm{mL}$ catalase, $1.0 \mathrm{mM}$ phenylalanine, $1.01 \mu \mathrm{M} \mathrm{PAH}_{\mathrm{ox}}$, and $26-105 \mu \mathrm{M} 6 \mathrm{MPH}_{4}$. Since in $100 \mathrm{mM}$ potassium phosphate at $\mathrm{pH} 6.8$ and $25^{\circ} \mathrm{C}_{6} 6 \mathrm{MPH}_{4}$ will autooxidize to the extent of $20 \%$ oxidized in about $10 \mathrm{~min}$, fresh $6 \mathrm{MPH}_{4}$ was prepared frequently. Further, catalase was added to the pterin solution to reduce the rate of autooxidation. The spectrophotometer instrument settings included temperature control at $25 \pm 0.5^{\circ} \mathrm{C}, 0.3-\mathrm{mm}$ slit width, $1.86-\mathrm{cm}$ cuvette path length, and a $1-\mathrm{ms}$ time constant. The rate of $4 \mathrm{a}-\mathrm{OH}-$ $6 \mathrm{MPH}_{4}$ formation was monitored at $244 \mathrm{~nm}$. The differential molar extinction coefficient for $6 \mathrm{MPH}_{4}$ reacted to $4 \mathrm{a}-\mathrm{OH}$ $6 \mathrm{MPH}_{4}$ at $244 \mathrm{~nm}$ is $12500 \mathrm{M}^{-1} \mathrm{~cm}^{-1}$ (Lazarus et al., 1983). A record of each run was made by photographing the absorbance vs. time output displayed on the oscilloscope screen. The photographs were then digitized and converted into 4a$\mathrm{OH}-6 \mathrm{MPH}_{4}$ concentration vs. time data.

PAH specific activity was measured by using assay 2 conditions previous to all stopped-flow experiments, both by conventional means on a Gilford spectrophotometer and in the stopped-flow instrument. The enzyme as measured by stopped-flow spectrophotometry was found to exhibit $38 \%$ lower specific activity than that measured by conventional means.

Coupling of Cofactor Used to Product Formed at Low Enzyme Turnover. The yield of tyrosine produced relative to
$6 \mathrm{MPH}_{4}$ cofactor used was examined in systems where $6 \mathrm{MPH}_{4}$ to $\mathrm{PAH}_{\mathrm{ox}}$ molar stoichiometric ratios varied from 0.04 to 29.4 . Air-saturated assays containing $0.1 \mathrm{M}$ potassium phosphate, $\mathrm{pH} 6.8,50 \mu \mathrm{g} / \mathrm{mL}$ catalase, $1.0 \mathrm{mM}$ phenylalanine, and 10.0 $\mu \mathrm{M} \mathrm{PAH}_{\mathrm{ox}}\left(3.29 \mu \mathrm{M} \mathrm{PAH}_{\mathrm{act}}\right)$ were initiated by addition of from 0.38 to $292 \mu \mathrm{M} 6 \mathrm{MPH}_{4}$. The assays were mixed in open tubes, reacted at room temperature for $15 \mathrm{~min}$, and quenched by addition of $0.1 \mathrm{~mL}$ of $30 \%$ trichloroacetic acid. Tyrosine concentrations were determined by assay 3 . Examination of unreacted $6 \mathrm{MPH}_{4}$ remaining after the 15 -min incubation was conducted by quenching $350 \mu \mathrm{L}$ of assay solution into 18.8 $\mu \mathrm{M}$ 2,6-dichloroindophenol $\left(\epsilon_{600} \simeq 16000\right.$ for the oxidized form of the dye) in $200 \mathrm{mM}$ potassium phosphate, $\mathrm{pH} \mathrm{6.8,}$ and measuring the amount of dye reduction.

Determination of the Absence of 4a-OH-6MPH 4 as an Intermediate in the Pre-Steady-State Oxidation of $6 \mathrm{MPH}_{4}$ by $P A H$. A reaction containing, after mixing, 6.1 $\mu \mathrm{MPAH}_{\mathrm{ox}}$ and $7.6 \mu \mathrm{M} 6 \mathrm{MPH}_{4}$, with no phenylalanine present, was conducted in $20 \mathrm{mM}$ Tris buffer at $\mathrm{pH} 8.2$ in the stopped-flow spectrophotometer. This reaction was examined at two wavelengths, 244 and $334 \mathrm{~nm}$. The molar extinction coefficients for the three cofactor species of interest are, at $244 \mathrm{~nm}, 4000,16500$, and $7200 \mathrm{M}^{-1} \mathrm{~cm}^{-1}$ for $6 \mathrm{MPH}_{4}, 4 \mathrm{a}-\mathrm{OH}-6 \mathrm{MPH}_{4}$, and quinonoid-6 $\mathrm{MPH}_{2}$, respectively, and, at $334 \mathrm{~nm}, 940,400$, and 4700 $\mathrm{M}^{-1} \mathrm{~cm}^{-1}$ for $6 \mathrm{MPH}_{4}, 4 \mathrm{a}-\mathrm{OH}-6 \mathrm{MPH}_{4}$, and quinonoid-6 $\mathrm{MPH}$, respectively. Duplicate reactions were run at each wavelength, and the results were averaged.

Titration of Phenylalanine Hydroxylase by $6 \mathrm{MPH}_{4}$ in the Presence of a Fe ${ }^{2+}$ Trap. The reduction of ferric iron in $\mathrm{PAH}_{0 \mathrm{x}}$ upon titration with $6 \mathrm{MPH}_{4}$ was monitored by observing the formation of an $o$-phenanthroline-Fe(II) complex at $510 \mathrm{~nm}$ (Schilt, 1969). Samples containing 19-20 $\mu \mathrm{M}$ total PAH (0.9 $\mathrm{Fe} / 50000$-dalton subunit), $24 \mathrm{mM}$ Tris, $240 \mathrm{mM}$ potassium chloride, $40 \mu \mathrm{M}$ EDTA, and $2 \mathrm{mM}$ o-phenanthroline were titrated with sequential additions of $1.7-2.0 \mathrm{nmol}$ of $6 \mathrm{MPH}_{4}$ in $0.005 \mathrm{~N}$ hydrochloric acid. The experiment was also performed in the presence of $50 \mu \mathrm{g} / \mathrm{mL}$ catalase. The absorbance change at $510 \mathrm{~nm}$ was monitored and related to the concentrated of the $\left.[\mathrm{Fe} \text { (phen })_{3}\right]^{2+}$ complex by $\epsilon_{510}=11100 \mathrm{M}^{-1} \mathrm{~cm}^{-1}$. Nonspecific changes in the 510 -nm absorbance were subtracted by monitoring two control reactions, one involving addition of $6 \mathrm{MPH}_{4}$ to the system described above, but without enzyme, and the other involving addition of $0.005 \mathrm{~N}$ hydrochloric acid (without $6 \mathrm{MPH}_{4}$ ) to the system described above. Oxidation of $6 \mathrm{MPH}_{4}$ was monitored at $334 \mathrm{~nm}$ (assay 1).

Reductive Titration of Phenylalanine Hydroxylase by $\mathrm{Na}_{2} \mathrm{~S}_{2} \mathrm{O}_{4}$. The reduction of ferric iron in $\mathrm{PAH}_{\mathrm{ox}}$ was also effected by titration of (for example) $6.24 \mu \mathrm{M}$ total PAH in $0.1 \mathrm{M}$ potassium phosphate, $\mathrm{pH} 7.0$, with $0.367 \mathrm{mM}$ sodium dithionite. Solutions were deoxygenated on an anaerobic gas train (Williams et al., 1979) utilizing argon, and titrations were performed by using an anaerobic spectrophotometric titration cell (Williams et al., 1979). Reductive titrations were conducted in a Cary 118 spectrophotometer using a specially constructed wooden box to cover the sample compartment with the titration cell in place. The extent of PAH reduction was followed by monitoring the decrease in protein absorbance at $280 \mathrm{~nm}$ (Marota \& Shiman, 1984). A differential extinction coefficient between oxidized and dithionite-reduced PAH was determined to be $\epsilon_{280}{ }^{\mathrm{PAH}_{0 x}}-\mathrm{PAH}_{\text {red }}=5840 \pm 225 \mathrm{M}^{-1} \mathrm{~cm}^{-1}$ ( $n$ $=4$ ). Sodium dithionite stock solutions were prepared in

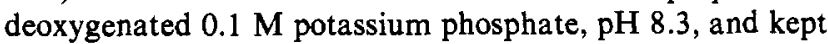
on ice under an argon head. Under these conditions, the dithionite lost its reducing capacity with $k_{\text {obsd }}$ of $0.11 \mathrm{~h}^{-1}$. Dithionite was standardized against FAD by using an ex- 
tinction coefficient of $11300 \mathrm{M}^{-1} \mathrm{~cm}^{-1}$ at $450 \mathrm{~nm}$ for the oxidized flavin (Dixon, 1971a,b). FAD was prepared in deoxygenated $0.1 \mathrm{M}$ potassium phosphate, $\mathrm{pH} 7.0$, and was found to be stable throughout the course of a day.

Titration of Phenylalanine Hydroxylase by $\mathrm{Na}_{2} \mathrm{~S}_{2} \mathrm{O}_{4}$ in the Presence of $\mathrm{Fe}^{2+}$ Trap. The dithionite reduction of PAH was carried out in the presence of $a$-phenanthroline. Deoxygenated samples containing $6.24 \mu \mathrm{M}$ total PAH, $1 \mathrm{mM}$ ophenanthroline, and $0.1 \mathrm{M}$ potassium phosphate, $\mathrm{pH} 7.0$, were titrated as above. Reduction was followed by monitoring the formation of the $\left[\mathrm{Fe}(\text { phen })_{3}\right]^{2+}$ complex at $510 \mathrm{~nm}$.

Coupling of Cofactor Used to Product Formed for Nonprereduced and Dithionite-Prereduced Phenylalanine Hydroxylase. The coupling experiment described above was repeated with both nonprereduced PAH and dithioniteprereduced PAH. Enzyme was reductively titrated to 0.5 $\mathrm{Na}_{2} \mathrm{~S}_{2} \mathrm{O}_{4} / \mathrm{PAH}$ subunit as described above, and as a control, another sample of PAH was handled similarly with the exception that a volume of $0.1 \mathrm{M}$ potassium phosphate, $\mathrm{pH} 8.3$, buffer (no dithionite) was added equivalent to the volume of dithionite added to make reduced PAH. Transfers of PAH were conducted in a glove box under an argon atmosphere. Assays containing initially anaerobic solutions of $0.1 \mathrm{M}$ potassium phosphate, $\mathrm{pH} 7.0,50 \mu \mathrm{g} / \mathrm{mL}$ catalase, $1.0 \mathrm{mM}$ phenylalanine, $3.70 \mu \mathrm{MPAH}_{\mathrm{ox}}$ or $\mathrm{PAH}_{\text {red }}\left(\mathrm{PAH}_{\text {act }}=1.33 \mu \mathrm{M}\right.$ for each), and $0.58-115.5 \mu \mathrm{M} 6 \mathrm{MPH}_{4}$ were initiated by intermittent purging of the head gas with air followed by gentle agition. After $60 \mathrm{~min}$, the assays were quenched by addition of $0.1 \mathrm{~mL}$ of $30 \%$ trichloroacetic acid. Tyrosine concentrations were determined by assay 3 .

Computer Simulation. All computer simulations were done on an IBM 3033 processor complex running under OS/VS2 MVS. Simulations were performed by Chemical Reaction Analysis and Modeling System (CRAMS), an integrated system of Fortran and OS Assembler modules designed to simulate reaction progress data (Butler \& DeMaine, 1975; DMaine, $1980 \mathrm{a}, \mathrm{b}$ ). The simulator module of the system uses a predictor-corrector algorithm started by a Runge-Kutta method to solve the applicable system of differential equations.

Samples for EPR. PAH was dissolved in Tris buffer ( 30 $\mathrm{mM}, \mathrm{pH}$ 7.25), containing $0.3 \mathrm{M}$ potassium chloride and 50 $\mu \mathrm{M}$ EDTA, for EPR measurements. Catalase $(30000-40000$ units $/ \mathrm{mg}, 45 \mathrm{mg} / \mathrm{mL}, 0.1 \%$ thymol) was diluted to the desired concentration in the above buffer when it was used as an EPR signal intensity standard. Aliquots of the commercial catalase preparation were added directly to the PAH solution when catalase was employed to scavenge hydrogen peroxide. Transferrin used as a signal intensity standard was prepared from apotransferrin and nitrilotriacetic acid-ferric complex by the procedure of Bates \& Schlabach (1973) and Bates \& Wernicke (1971) in a buffer of final composition of $10 \mathrm{mM}$ Tris (pH 7.1) and 0.1 M sodium perchlorate to which was added $10 \mathrm{mM}$ bicarbonate. The degree of saturation of the two iron sites were estimated from the optical density at $\mathbf{4 7 0}$ $\mathrm{nm}\left(\epsilon=2.5 \times 10^{3} / \mathrm{cm}^{-1} \mathrm{M}^{-1}\right)$.

EPR Measurements. Electron paramagnetic resonance measurements were made on a Varian E109 spectrometer equipped with a low-power microwave bridge (E-102-04), reference arm, and an Oxford Instruments pumped helium ESR-10 cryostat and temperature control unit. Temperatures quoted in this paper are those at a thermocouple located just under the sample tube. Preliminary temperature calibration of this system using the $g_{\text {eff }} \sim 3.0$ signal of cytochrome $c$ (Slappendel et al., 1980) indicates that temperatures are highly reproducible but are probably higher than indicated by the

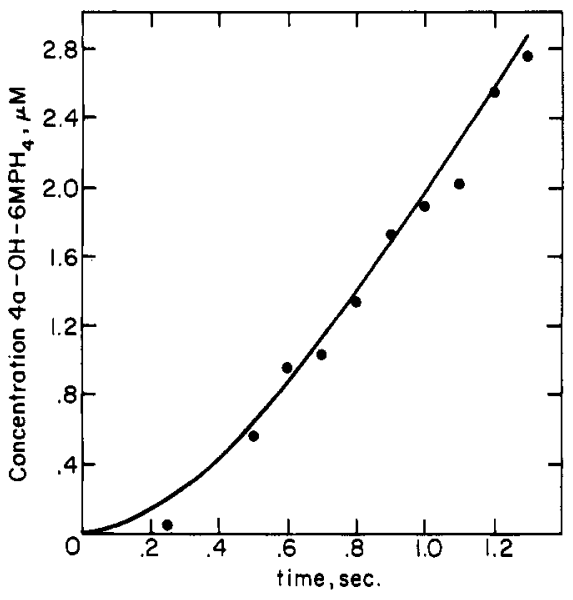

FIGURE 1: A representative stopped-flow spectrophotometric timeprogress curve representing formation of $4 \mathrm{a}-\mathrm{OH}-6 \mathrm{MPH}_{4}$. Reaction conditions are $1.01 \mu \mathrm{M} \mathrm{PAH}_{\mathrm{ox}}, 1.0 \mathrm{mM}$ phenylalanine, $50 \mu \mathrm{g} / \mathrm{mL}$ catalase, and $105 \mu \mathrm{M} 6 \mathrm{MPH}_{4}$ in $100 \mathrm{mM}$ potassium phosphate at $\mathrm{pH}$ 6.8. Instrument settings are described under Methods. The plotted points represent results of a stopped-flow run. The solid curve represents the results of a computer fit of the two-step mechanism presented under Results. The parameters used for this particular fit were $K_{\mathrm{S}}^{2}=45 \mu \mathrm{M}, k_{2}=12.0 \mathrm{~s}^{-1}$, and $k_{\mathrm{r}}=2.0 \times 10^{4} \mathrm{M}^{-1} \mathrm{~s}^{-1}$

thermocouple. To assure uniform temperature in the sample, the flow of helium gas over the sample was increased to a level where signal intensity was independent of flow rate. Samples were contained in a Pyrex apparatus of approximately $5-\mathrm{mL}$ volume with a side arm leading to a quartz-EPR tube and a three-way stopcock for evacuating the sample and anaerobic additions. Anaerobic additions of $6 \mathrm{MPH}_{4}$ in $0.01 \mathrm{M} \mathrm{HCl}$ were most conveniently made by evaporating a small aliquot on the side of the 5-mL bulb and avoiding admixture with the enzyme until the solution was degassed. EPR samples were usually $0.4 \mathrm{~mL}$ in volume. When glycerol was added to samples, it was Eastman spectral grade. When effective $g$ values $\left(g_{\text {eff }}\right)$ are used in the text, they refer to a calculation of $g_{\text {eff }}=h \nu /(\beta B)$ $=6600 / B$ where $\mathrm{B}$ is in units of gauss (EPR measurements were performed at $9237 \mathrm{MHz}$ ). The quantity of "EPR-visible" iron was estimated by double integration and comparison of portions of the double integral with those of standard samples that exhibit EPR signals in the portion of the spectrum of interest. Catalase was the standard for comparison for the region $g_{\text {eff }}$ from $\sim 5$ to 10 and monoferric transferrin was used for $g_{\text {eff }} \sim 3-5$. Standards and phenylalanine hydroxylase samples were measured under identical experimental conditions, except for instrument gain, and microwave powers well below saturation were used for each sample.

Results

Fit of Lag Kinetics to a Two-Step Mechanism. The kinetic data were obtained from stopped-flow spectrophotometric experiments designed to observe the formation of the $4 \mathrm{a}-\mathrm{OH}$ $6 \mathrm{MPH}_{4}$ species that is concomitant with tyrosine formation (Lazarus et al., 1981, 1982a,b). They typically showed a pre-steady-state lag of $t<0.5 \mathrm{~s}$ followed by a steady-state rate over the next $1 \mathrm{~s}$ (Figure 1). Under these conditions ( $1 \mathrm{mM}$ Phe and $0.1 \mathrm{M}$ potassium phosphate, $\mathrm{pH} 6.8$ ), the $4 \mathrm{a}-\mathrm{OH}$ $6 \mathrm{MPH}_{4}$ accumulates since the rate constant for its dehydration is $0.12 \mathrm{~s}^{-1}\left(t_{1 / 2} \simeq 6 \mathrm{~s}\right)$ so that the steady-state rate is simply the turnover of the enzyme. Experiments done at five $6 \mathrm{MPH}_{4}$ concentrations $(26-105 \mu \mathrm{M})$ showed that the rate constant characterizing the pre-steady-state lag phase was first order in $6 \mathrm{MPH}_{4}$. Since there was no indication of saturation by $6 \mathrm{MPH}_{4}$, the kinetic data were fit to the following abbreviated two-step mechanism featuring an initial PAH activation: 
step 1

$$
2 \mathrm{PAH}_{\mathrm{ox}}+6 \mathrm{MPH}_{4} \stackrel{k_{\mathrm{s}}}{\longrightarrow} 2 \mathrm{PAH}_{\mathrm{red}}+\text { quinonoid-6 } \mathrm{MPH}_{2}
$$

step 2

$$
\mathrm{PAH}_{\mathrm{act}}+6 \mathrm{MPH}_{4} \underset{\mathrm{PAH}_{\mathrm{act}}+4 \mathrm{a}-\mathrm{OH}-6 \mathrm{MPH}_{4}+\text { tyrosine }}{\stackrel{K_{\mathrm{s}}{ }^{2}}{\rightleftharpoons}\left(\mathrm{PAH}_{\mathrm{act}} \cdot 6 \mathrm{MPH}_{4}\right) \frac{k_{2} \mathrm{Phe}^{2}}{\rightleftharpoons}}+\text { ty }
$$

where $\mathrm{PAH}_{\text {red }} \geq \mathrm{PAH}_{\text {act }}$. Although step 1 does not explicitly indicate the presence of phenylalanine, this substrate accelerates the flux through this step (Marota \& Shiman, 1984). Evidence that quinonoid-6 $\mathrm{MPH}_{4}$ is the product of step 1 is presented below. For enzyme samples exhibiting less than the maximal specific activity, only the $\mathrm{PAH}_{\text {act }}$ participates in step 2. Both the concentrations of phenylalanine and molecular oxygen are in excess of that for $6 \mathrm{MPH}_{4}$ and thus effectively remain constant.

A computer fit of the data to the above model yields a value of $k_{\mathrm{r}}=2 \times 10^{4} \mathrm{M}^{-1} \mathrm{~s}^{-1}$ employing $K_{\mathrm{S}}{ }^{2}=K_{\mathrm{M}}=45 \mu \mathrm{M}$, as determined by assay 1 conditions [also, Goodwin (1979) and Kaufman (1971)], and $k_{2}=12 \mathrm{~s}^{-1}$ and is shown in Figure 1. The stoichiometry of the initial reduction step is written presuming a $1 / 26 \mathrm{MPH}_{4} / \mathrm{PAH}_{\mathrm{ox}}$ subunit ratio in accord with results described below. Attempts to monitor directly the absorbance arising from the formation of quinonoid-6 $\mathrm{MPH}_{2}$ in step 1 were precluded by a compensating change in the $\mathrm{PAH}_{\text {red }}$ spectrum (Marota \& Shiman, 1984).

Absence of $4 a-\mathrm{OH}-6 \mathrm{MPH}_{4}$ as an Intermediate in Step 1. While it is known that $4 \mathrm{a}-\mathrm{OH}-6 \mathrm{MPH}_{4}$ is a cofactor intermediate in the enzymatic production of tyrosine from phenylalanine (step 2), it can be shown that the $4 \mathrm{a}-\mathrm{OH}-6 \mathrm{MPH}_{4}$ intermediate is not found upon examination of the presteady-state oxidation of $6 \mathrm{MPH}_{4}$ by PAH (step 1). The reaction of $\mathrm{PAH}_{\mathrm{ox}}$ and $6 \mathrm{MPH}_{4}$ to give $\mathrm{PAH}_{\text {red }}$ and quinonoid$6 \mathrm{MPH}_{2}$ in the absence of phenylalanine was followed by stopped-flow spectrophotometry at two wavelengths. The

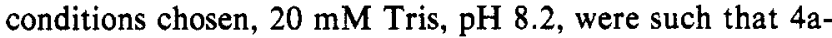
$\mathrm{OH}-6 \mathrm{MPH}_{4}$, if it were an intermediate, would have exhibited an appreciable lifetime (Lazarus et al., 1981). The rate constant for dehydration of $4 \mathrm{a}-\mathrm{OH}-6 \mathrm{MPH}_{4}$ to quinonoid$6 \mathrm{MPH}_{2}$ was $0.3 \mathrm{~min}^{-1}$. Given the relative magnitudes of the molar extinction coefficients for $6 \mathrm{MPH}_{4}$, quinonoid- $6 \mathrm{MPH}_{2}$, and $4 \mathrm{a}-\mathrm{OH}-6 \mathrm{MPH}_{4}$, it can be seen that a comparison of the initial slopes of the absorbance vs. time curves at the two wavelengths, 244 and $334 \mathrm{~nm}$, would directly identify whether or not $4 \mathrm{a}-\mathrm{OH}-6 \mathrm{MPH}_{4}$ was an intermediate in this reaction. If $4 \mathrm{a}-\mathrm{OH}-6 \mathrm{MPH}_{4}$ was an intermediate between $6 \mathrm{MPH}_{4}$ and quinonoid-6 $\mathrm{MPH}_{2}$, the initial slopes of the progress curves must differ in sign (either positive or negative $\Delta$ absorbance/time). If $6 \mathrm{MPH}_{4}$ was oxidized directly to quinonoid$6 \mathrm{MPH}_{2}$, the initial slopes must both be positive and be of similar magnitude.

Analysis of the data obtained from the experiments described above resulted in two reaction progress curves, one at each wavelength. At $244 \mathrm{~nm}$, the initial slope was 0.0209 $\Delta O D / \mathrm{min}$, and at $334 \mathrm{~nm}$, the initial slope was 0.0191 $\Delta \mathrm{OD} / \mathrm{min}$. These data support the direct oxidation of $6 \mathrm{MPH}_{4}$ to quinonoid-6 $\mathrm{MPH}_{2}$, with no $4 \mathrm{a}-\mathrm{OH}-6 \mathrm{MPH}_{4}$ intermediate involved in step 1.

Results of Cofactor-Product Coupling Experiments. Examination of the two-step mechanism offered above suggests that at stoichiometric amounts of $\mathrm{PAH}_{\mathrm{ox}}$ and $6 \mathrm{MPH}_{4}$, less than one molar equivalent of tyrosine would be expected to be produced due to oxidation of some of the pterin in step 1 to activate the PAH for tyrosine production in step 2 . This

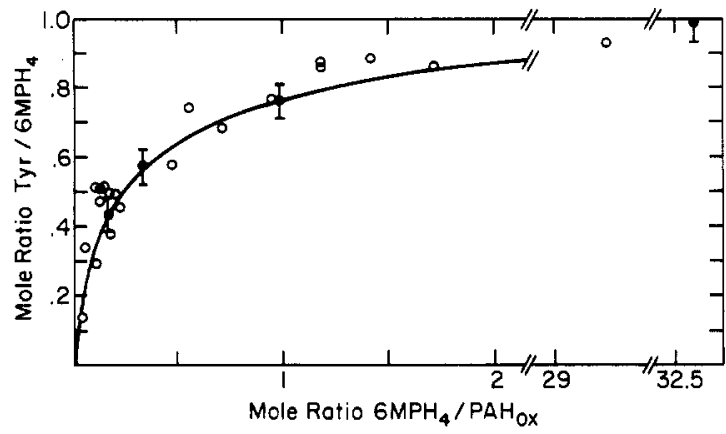

FIGURE 2: Uncoupling of [cofactor-added] to [tyrosine-produced] ratios at stoichiometric concentrations of $6 \mathrm{MPH}_{4}$ and $\mathrm{PAH}$. Addition of varying amounts of $6 \mathrm{MPH}_{4}$ to assays containing $10.0 \mu \mathrm{M} \mathrm{PAH}_{\mathrm{ox}}$ $\left(3.29 \mu \mathrm{M} \mathrm{PAH}_{\text {act }}\right), 1.0 \mathrm{mM}$ phenylalanine, and $50 \mu \mathrm{g} / \mathrm{mL}$ catalase in air-saturated $100 \mathrm{mM}$ potassium phosphate, $\mathrm{pH} 6.8$, resulted in production of less than a molar equivalence of tyrosine. The data were computer fit to the two-step mechanism presented under Results where $K_{\mathrm{S}}^{2}=45 \mu \mathrm{M}, k_{2}=12.0 \mathrm{~s}^{-1}$, and $k_{\mathrm{r}}=2.0 \times 10^{4} \mathrm{M}^{-1} \mathrm{~s}^{-1}$. The computer fit is shown here as the solid curve.

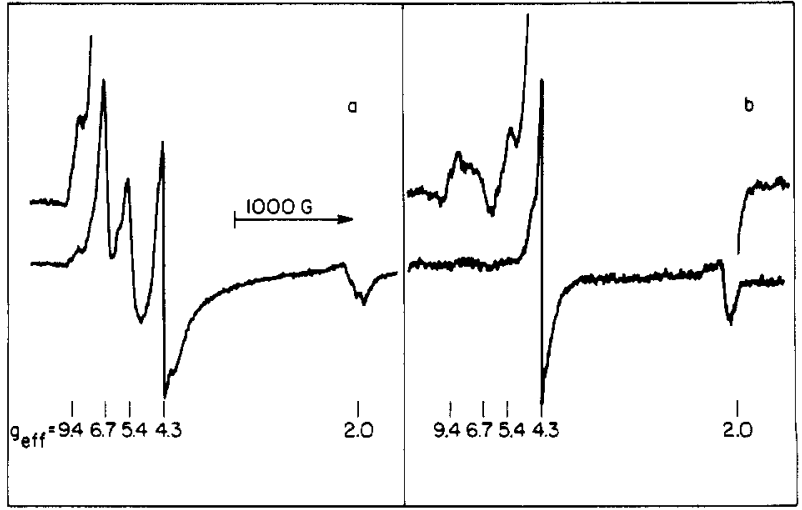

FIGURE 3: (a) Paramagnetic resonance spectrum of $\mathrm{PAH}_{\mathrm{ox}}(20.2$ $\mathrm{mg} / \mathrm{mL}$ total PAH; specific activity $=5.0 ; 0.87$ iron/subunit; 0.35 $\mathrm{mM}, \mathrm{pH}^{4^{\circ} \mathrm{C}} 7.25$ ) is shown for a frozen sample at $5 \mathrm{~K}$. The upper insert gives a 10 -fold amplification to show the low-field features. Instrumental settings are the following: modulation amplitude: 20 gauss; receiver gain: $8 \times 10^{3}$; microwave power $0.1 \mathrm{~mW}$; time constant $0.128 \mathrm{~s}$; scan time $16 \mathrm{~min}$. $g$ values of prominent special features are given. (b) The EPR spectrum (at $10 \mathrm{~K}$ ) of the enzyme after phenylalanine addition is shown. $\mathrm{PAH}_{0 \mathrm{x}}$ concentration is $85 \mu \mathrm{M}$, and that of phenylalanine is $2.4 \mathrm{mM}$. Instrumental settings were the following: gain $2 \times 10^{4}$; power $0.05 \mathrm{~mW}$; time constant $0.25 \mathrm{~s}$; scan time $16 \mathrm{~min}$. The low-field insert is amplified 10 times. The sample tubes were different in (a) and (b), and thus, the $g_{\text {eff }}=2$ regions cannot be compared directly due to differing background signals.

coupling was studied by preparing different assay samples containing $\mathrm{PAH}$, phenylalanine, $\mathrm{O}_{2}$, and catalase (required to protect $\mathrm{PAH}$ from inactivation during reaction) and titrating them with $6 \mathrm{MPH}_{4}$ in molar ratios relative to $\mathrm{PAH}_{\mathrm{ox}}$ from 0.04 to 29.4. The tyrosine produced in each of these reaction samples was quantitated, and the ratio of tyrosine produced to $6 \mathrm{MPH}_{4}$ added was examined. The results are shown in Figure 2, along with the predicted ratios determined by computer fit using the two-step mechanism introduced above. The computer fit used $k_{2}=12 \mathrm{~s}^{-1}, K_{\mathrm{S}}{ }^{2}=45 \mu \mathrm{M}$, and $k_{\mathrm{r}}=2.0 \times$ $10^{4} \mathrm{M}^{-1} \mathrm{~s}^{-1}$.

A control experiment was performed to determine that all of the $6 \mathrm{MPH}_{4}$ had been oxidized and was not simply unreacted at the end of the reaction. Quenching reaction samples with 2,6-dichloroindophenol at the end of the reaction revealed that no appreciable $6 \mathrm{MPH}_{4}$ remained unreacted. Also, under the conditions noted above, autoxidation of $6 \mathrm{MPH}_{4}$ would be expected to be slow relative to PAH utilization of the pterin.

$E P R$ Spectra of $P A H_{\mathrm{ox}}$. A spectrum characteristic of $\mathrm{PAH}_{\mathrm{ox}}$ in frozen solution at $5 \mathrm{~K}$ is shown in Figure 3a. There 


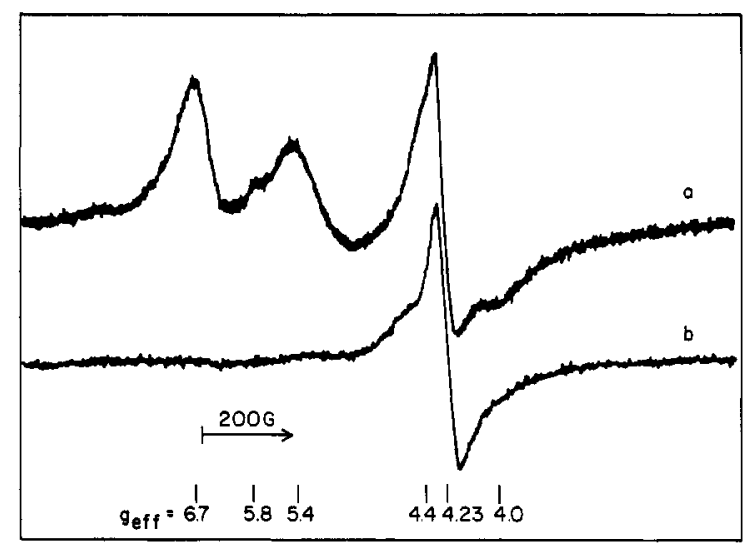

FIGURE 4: Portion of the EPR spectra of samples corresponding to (a) and (b) in Figure 3 is shown expanded here for magnetic fields from 400 to $2400 \mathrm{G}$. In this case, both spectra were recorded at 10 $K$. These plots are representative of ones used for double integration of spectra from phenylalanine hydroxylase and standards. The experimental conditions are the following: (a) receiver gain $4 \times 10^{4}$; power $0.02 \mathrm{~mW}$; time constant $0.5 \mathrm{~min}$.; scan time $1 \mathrm{~h}$; (b) gain 1.6 $\times 10^{4}$; power $0.05 \mathrm{~mW}$; time constant $0.25 \mathrm{~s}$; scan time $16 \mathrm{~min}$.

are maxima at effective $g$ values of 6.7 and 5.4, a region from which no background absorption from buffer or apparatus is observed. A shoulder at $g_{\text {eff }}=5.8$ is also apparent in the spectrum shown. The origin of the signals near $g_{\text {eff }}=4.3$ is more difficult to assign, however, because signals at this position can arise from iron contaminants in buffer or from iron bound nonspecifically to protein as well as from the functional iron in some enzymes. At the most, $10 \%$ of the magnitude of the $g_{\text {eff }}=4.3$ signal in Figure $3 \mathrm{a}$ may be attributed to buffer and background. Further discussion of the origin of the remaining $g_{\text {eff }}=4.3$ signal is given below. There are also two shoulders at $g$ values of approximately 9.4 and 8.7 in the spectrum shown in Figure 3a. Figure 4 is an expansion of the low-field regions of the spectra shown in Figure 3 .

The position of obvious maxima, and some shoulders, in the iron EPR spectra of phenylalanine hydroxylase are summarized in Table I. In the low-field region, the data are consistent with absorption from the lower Kramer's doublet of at least two species with distinctly different ligand environments for iron: one at $g_{\text {eff }}$ values 9.4 and/or 8.7 and another at $g_{\text {eff }}=6.7$ and 5.4. The peaks at $g_{\text {eff }}=6.7$ and 5.4 appear invariant in line shape over a temperature range from 4 to $\sim 50$ $\mathrm{K}$ and microwave powers to $5 \mathrm{~mW}$. It is reasonable to assume that the $g_{\text {eff }}=6.7$ and 5.4 features are the "turning points" for the $g_{x}$ and $g_{y}$ components of a doublet which should also include a $g_{z}$ component near $g_{\text {eff }}=2$. Specific assignments in the $g_{\text {eff }}=2$ region will require further studies and background subtractions of very concentrated enzyme preparations.

The significance of two peaks, rather than one, at $g_{\text {eff }}=9.4$ and 8.7 is not clear, but at least one of these should be attributed to the lower Kramer's doublet of the iron which also gives a signal in the $g_{\text {eff }}=4.3$ region (middle doublet). The shoulder at $g_{\text {eff }}=5.8$ increases in intensity relative to absorption at $g_{\text {eff }}=6.7$ and 5.4 as temperature is raised from $\sim 10$ to $20 \mathrm{~K}$. This shoulder may therefore be absorption from the middle Kramer's doublet of the portion of iron that gives the $g_{\text {eff }}=6.7$ and 5.4 signals (Que, 1980). Preliminary studies of the temperature dependence of the low-field region of the EPR spectrum of the $\mathrm{PAH}_{\text {ox }}$ enzyme make it clear that the product of intensity times temperature of all of the signals at $g_{\text {eff }}=9.4,8.7,6.7$, and 5.4 increases as temperature is lowered; thus, these features may be assigned to lower Kramer's doublets.
Table I: EPR Data for High-Spin States of

Phenylalanine Hydroxylase

\begin{tabular}{|c|c|c|}
\hline \multirow[b]{2}{*}{ sample ${ }^{a}$} & \multicolumn{2}{|c|}{$g_{\text {eff }}$ values } \\
\hline & low field $b$ & midfield $^{b}$ \\
\hline $\begin{array}{l}\mathrm{PAH}_{\mathrm{ox}} \\
\text { species I }\end{array}$ & $\begin{array}{l}6.7 \\
5.8(\mathrm{~s})^{c} \\
5.4\end{array}$ & \\
\hline species II & $\begin{array}{l}9.4 \\
8.7\end{array}$ & $\begin{array}{l}4.4 \\
4.23 \\
4.0\end{array}$ \\
\hline $\begin{array}{l}\text { phenylalanine- } \\
\text { saturated } \text { PAH }_{\text {ox }} d\end{array}$ & $\begin{array}{l}9.4 \\
8.7 \\
7.7 \\
5.4\end{array}$ & $\begin{array}{l}4.55 \\
4.2\end{array}$ \\
\hline
\end{tabular}

${ }^{a}$ Samples were $0.1-0.35 \mathrm{mM}$ in $\mathrm{PAH}_{\mathrm{Ox}}$ and were measured in frozen solutions at $\sim 10 \mathrm{~K}$. ${ }^{b}$ These regions were chosen to correspond to positions expected for the lower (low-field) and middle (midfield) Kramer's doublets. ${ }^{c}$ Shoulder. ${ }^{d}$ From the $K_{d} \simeq 1$ $\mathrm{mM}$ for Phe, the enzyme should be $71 \%$ saturated.

Effects of Ligand Binding on the EPR Spectra of PAH. In contrast to the EPR spectra of $\mathrm{PAH}_{\mathrm{ox}}$, when phenylalanine is added to phenylalanine hydroxylase, the EPR spectrum now has a signal around $g_{\text {eff }}=4.3$ as the only dominant feature (Figure 3b). At higher magnification (inset), turning points at $g_{\text {eff }}=9.4-8.7$ are seen, as well as some broad low-intensity absorption of $g_{\text {eff }}$ from 5 to 8 . We have examined the EPR spectra of samples after several other additions (or deletions) to the enzyme in order to determine the general requirements for the loss of signals at $g_{\text {eff }}=6.7$ and 5.4. Removal of oxygen from the $\mathrm{PAH}_{\mathrm{ox}}$ enzyme leaves the spectrum shown in Figure 3a unaltered. A 20 -fold, or greater, molar excess of phenylalanine over enzyme gives a spectrum of the type shown in Figure $3 \mathrm{~b}$ regardless of whether the addition is made in the presence or absence of air. The effect of phenylalanine is reversible after removal of phenylalanine by gel filtration. Addition of the inhibitor, glycerol (Marota \& Shiman, 1984), to $10 \%(\mathrm{v} / \mathrm{v})$ also results in conversion of the EPR line shape from that of the $\mathrm{PAH}_{\mathrm{ox}}$ to one having features similar to, although not identical with, that shown in Figure 3b. The EPR spectral changes effected by phenylalanine or glycerol additions cannot be attributed to complexes of the enzyme-bound iron with product (tyrosine) since no $6 \mathrm{MPH}_{4}$ was present. It is more difficult to evaluate the effects of addition of $6 \mathrm{MPH}_{4}$ to enzyme solutions because, in the presence of oxygen, this cofactor is oxidized and precautions must be taken against hydrogen peroxide formation. However, addition of $1 \mathrm{~mol}$ of pterin $/ \mathrm{mol}$ of $\mathrm{PAH}_{\mathrm{ox}}$ in the absence of air again results in the loss of signals at $g_{\text {eff }}=6.7$ and 5.4 .

Assignment of EPR Signals to Active and Inactive Iron. The integrated intensity of the $\mathrm{PAH}_{\mathrm{ox}}$ signal in the $g_{\text {eff }}=4.3$ region was found to correspond to a variable fraction of the total iron in different samples. For the present, in the absence of simulation of the EPR spectra, an estimate of EPR-visible iron was made by comparing the double integral of a portion of the spectrum with that of a standard sample having a similar line shape and field dependence so that correction by the $1 / \mathrm{g}$ intensity factor (Aasa \& Vanngard, 1975) could be omitted. The standard for comparison with the native $\mathrm{PAH}_{\mathrm{ox}}$ signals in the $g_{\text {eff }}=6.7$ and 5.4 regions was catalase; in the $g_{\text {eff }}=3-5$ region, the ferric-nitrilotriacetate-transferrin complex (Bates \& Schlabach, 1973) was used. Figure 5 shows a linear relation between EPR intensity in this region and the specific activity of various preparations of $\mathrm{PAH}_{\mathrm{ox}} ; g_{\text {eff }}=4.3$ intensity increases as specific activity decreases. On this basis, that signal is assigned to ferric iron that is bound to the enzyme in an 


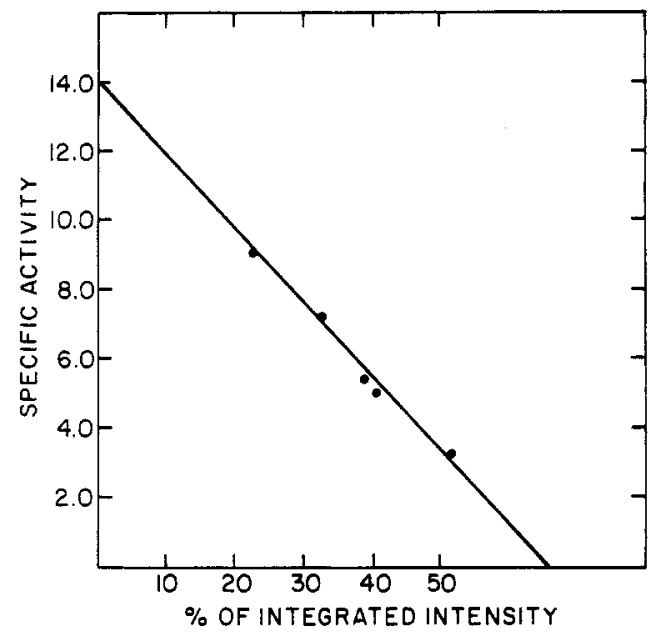

FIGURE 5: Specific activity of phenylalanine hydroxylase, taken before EPR measurement, is plotted as a function of the integrated intensity of the portion of the EPR spectrum between $g_{\text {eff }}=5$ and $g_{\text {eff }}=3$. The monoferric transferrin EPR spectrum was recorded under the same instrument settings, and this spectrum was used as the standard for integration.

inactivatable state. We are unable to say whether the intercept on the abscissa of Figure 5 at $\sim 65 \%$ is due to inaccuracies in our comparative integration procedure or to a fraction of the inactive iron being ferrous and EPR invisible.

In samples of PAH, the signal at $g_{\text {eff }}=4.3$ is relatively insensitive to temperature variations around $10 \mathrm{~K}$, so that temperature was chosen for integration of the $g_{\text {eff }}=4.3$ region. However, as expected for a lower Kramer's doublet, the $g_{\text {eff }}$ $=6.7$ and 5.4 intensities are extremely temperature dependent at and below $10 \mathrm{~K}$, so we elected to quantitate a signal in the $g_{\text {eff }}=6.7-5.4$ region at $\sim 20 \mathrm{~K}$ where the temperature dependence of intensity is smaller even though the total EPR amplitude is diminished considerably at this temperature. The specific activity of one concentrated sample of enzyme was 5.0 units $/ \mathrm{mg}$, which is $35 \%$ that of fully active $\mathrm{PAH}_{\mathrm{ox}}$ (Shiman \& Jefferson, 1982). Compared to the catalase standard at $20 \mathrm{~K}$, the $g_{\text {eff }}=5-10$ region of this sample of $\mathrm{PAH}_{0 \mathrm{x}}$ had an integrated intensity corresponding to $30 \%$ of the total iron content. We conclude that the $g_{\text {eff }}=6.7$ and 5.4 maxima in the EPR spectra of $\mathrm{PAH}_{\mathrm{ox}}$ are attributable to the catalytically active iron in the native enzyme. Integration of the $g_{\text {eff }}=5-10$ region in a number of other spectra recorded at $10 \mathrm{~K}$ confirms the correlation of intensity in the $g_{\text {eff }}=5-10$ region with the fraction of catalytically active enzyme. Thus, when the $g_{\text {eff }}$ $=4.3$ signals are included, most of the iron in the $\mathrm{PAH}_{\mathrm{ox}}$ is ferric and EPR visible.

Titration of Phenylalanine Hydroxylase by $6 \mathrm{MPH}_{4}$ in the Presence of a Fe $e^{2+}$ Trap. The titration of phenylalanine hydroxylase by $6 \mathrm{MPH}_{4}$ in the presence of $\mathrm{O}_{2}$ was carried out with $o$-phenanthroline in the solution. The results obtained by monitoring $510 \mathrm{~nm}$ [the $\lambda_{\max }$ for $\left[\mathrm{Fe}(\text { phen) })_{3}\right]^{2+}$ (Schilt, 1969)] as a function of $6 \mathrm{MPH}_{4}$ addition are shown in Figure 6A. The three important features are the following: (i) reduction of the enzyme by $6 \mathrm{MPH}_{4}$ must form $\mathrm{Fe}^{2+}$ that is then trapped by the chelator; (ii) the stoichiometry for iron removal averages $0.5 \pm 0.16 \mathrm{MPH}_{4} /$ subunit for total $\mathrm{PAH}$ whose specific activity ranges from 3 to 7 ; (iii) $>80 \%$ of the total iron per subunit is removed by the reduction/chelation process. Attempts to quantitate quinonoid formation after iron removal revealed that each further addition of $6 \mathrm{MPH}_{4}$ was accompanied by continuing quinonoid formation.

Titration of Phenylalanine Hydroxylase by $\mathrm{Na}_{2} \mathrm{~S}_{2} \mathrm{O}_{4}$. Since the results of the preceding experiment appear to indicate that

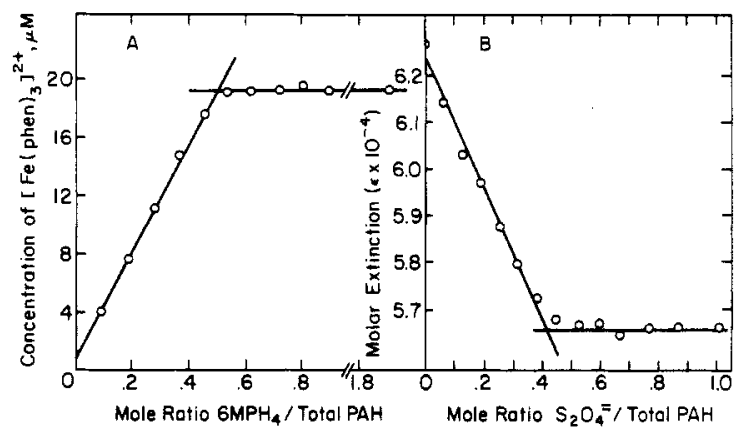

FIGURE 6: (A) Reduction of ferric iron in $\mathrm{PAH}_{\mathrm{ox}}$ to ferrous iron upon titration with $6 \mathrm{MPH}_{4}$ was monitored by observing the formation of an o-phenanthroline-Fe(II) complex at $510 \mathrm{~nm}$ (Schilt, 1969). A solution of $19 \mu \mathrm{M}$ total PAH in $24 \mathrm{mM}$ Tris, $\mathrm{pH} 7.0,240 \mathrm{mM}$ potassium chloride, $40 \mu \mathrm{M}$ EDTA, and $2 \mathrm{mM} o$-phenanthroline was titrated with aliquots of $1.7 \mathrm{nmol}$ of $6 \mathrm{MPH}_{4}$. (B) The reduction of $\mathrm{PAH}$ by sodium dithionite was monitored by following the decrease in absorbance at $280 \mathrm{~nm}$. The stoichiometry of five such reductions averaged at $0.52 \pm 0.09 \mathrm{Na}_{2} \mathrm{~S}_{2} \mathrm{O}_{4}$ /total PAH subunit. The experimental conditions for the titration shown above are $6.24 \mu \mathrm{M}$ total

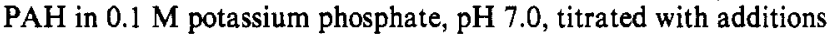
of $0.367 \mathrm{mM} \mathrm{Na}_{2} \mathrm{~S}_{2} \mathrm{O}_{4}$.

each PAH subunit iron center undergoes a one-electron reduction, the enzyme was titrated with another reducing agent, sodium dithionite. The dithionite titration of PAH is shown in Figure 6B. The stoichiometry obtained over five such titrations averages $0.52 \pm 0.09 \mathrm{Na}_{2} \mathrm{~S}_{2} \mathrm{O}_{4}$ /total PAH subunit or, since dithionite is a two-electron-reducing agent (Cotton \& Wilkinson, 1972), 1.06 electrons/PAH subunit. Enzyme reduced by 1.25 mol equiv of dithionite exhibited $86 \%$ of the $\mathrm{PAH}_{\mathrm{ox}}$ specific activity. Both the fluorescence spectra and the UV spectra of dithionite-reduced PAH (data not shown) are qualitatively similar to those of $6 \mathrm{MPH}_{4}$-reduced $\mathrm{PAH}$ (Marota \& Shiman, 1984), although in the case of the UV spectra, the differential extinction coefficient between anaerobic solutions of $\mathrm{PAH}_{\mathrm{ox}}$ and the dithionite-reduced $\mathrm{PAH}, \epsilon_{280} \mathrm{PAH}_{\mathrm{ox}}-\mathrm{PAH}_{\mathrm{red}}=$ $5840 \mathrm{M}^{-1} \mathrm{~cm}^{-1}$, is about twice the magnitude of that reported for $6 \mathrm{MPH}_{4}$-reduced PAH.

As with $6 \mathrm{MPH}_{4}$-reduced PAH, the protein locus of the added electron is the iron center. This was shown by titrating PAH with dithionite in a system containing the ferrous iron chelator, 0 -phenanthroline. The resulting titration plot of $\left.[\mathrm{Fe} \text { (phen) })_{3}\right]^{2+}$ vs. mole ratio $\mathrm{Na}_{2} \mathrm{~S}_{2} \mathrm{O}_{4} /$ total PAH subunit (data not shown) indicates a stoichiometry of $0.46 \mathrm{Na}_{2} \mathrm{~S}_{2} \mathrm{O}_{4} /$ subunit, consistent with that reported above.

In order to determine whether dithionite-reduced PAH is sufficiently activated for catalysis, the cofactor-product coupling experiment was repeated with both $\mathrm{PAH}_{\mathrm{ox}}$ and dithionite-reduced $\mathrm{PAH}_{\text {red. }}$. The results are depicted in Figure 7, with dithionite-reduced PAH giving an averaged straight line at $0.93 \mathrm{Tyr} / 6 \mathrm{MPH}_{4}$, while $\mathrm{PAH}_{\mathrm{ox}}$ gave a curved plot of decreasing slope very similar to that expected from Figure 2. The fact that this curved plot does not coincide with that of Figure 2 is probably due to the different ways in which each set of assays was initiated. A set of assays were run at 31.2 $6 \mathrm{MPH}_{4} /$ dithionite-reduced $\mathrm{PAH}_{\text {red }}$, a stoichiometry at which the system would show $98 \%$ coupling between tyrosine produced/cofactor added. These two points averaged at 0.92 Tyr $/ 6 \mathrm{MPH}_{4}$, which indicates that the line drawn at 0.93 $\mathrm{Tyr} / 6 \mathrm{MPH}_{4}$ for the dithionite-reduced $\mathrm{PAH}_{\text {red }}$ assays shows essentially $100 \%$ coupling. Therefore, $\mathrm{PAH}$ prereduced with one electron/PAH subunit can function catalytically without need to undergo any further reduction by $6 \mathrm{MPH}_{4}$.

Since the two-electron oxidation product of dithionite is sulfite, and sulfite is known to act as a two-electron-reducing agent itself (Dixon, 1971a), it was necessary to determine 


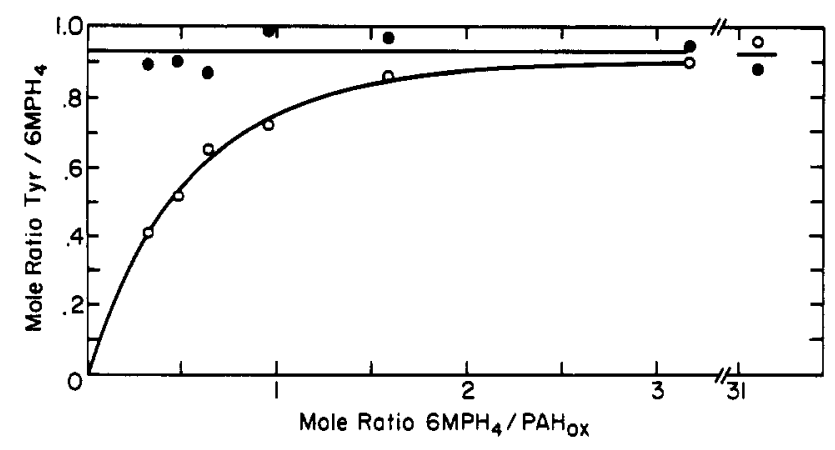

FIGURE 7: Degree of uncoupling of [cofactor-added] to [tyrosineproduced] ratios was examined by using both nonprereduced PAH $(0)$ and dithionite-prereduced PAH (৩). Assays consisted of anaerobic solutions of $0.1 \mathrm{M}$ potassium phosphate, $\mathrm{pH} 7.0,50 \mu \mathrm{g} / \mathrm{mL}$ catalase, $1.0 \mathrm{mM}$ phenylalanine, from 0.58 to $115.5 \mu \mathrm{M} 6 \mathrm{MPH}_{4}$, and either 3.70 $\mu \mathrm{M} \mathrm{PAH}_{\text {ox }}$ or $3.70 \mu \mathrm{M} \mathrm{PAH}_{\text {red }}$ (prereduced with dithionite to $0.5 \mathrm{Na}_{2} \mathrm{~S}_{2} \mathrm{O}_{4} / \mathrm{PAH}$ subunit). Active enzyme concentration was measured by assay 2 conditions to be $1.33 \mu \mathrm{MPAH}_{\text {act. }}$ Assay reactions were initiated by introduction of oxygen. The solid curve describing the uncoupling of the native PAH assays was drawn to fit the points and is not computer fit; the solid line describing the uncoupling of the reduced $\mathrm{PAH}$ assays was the average of the six points between 0 and 3.2 $6 \mathrm{MPH}_{4} / \mathrm{PAH}_{0 \mathrm{x}}$.

whether product sulfite was serving to further reduce PAH following dithionite reduction of the enzyme. An anaerobic sample of $\mathrm{PAH}$ in $0.1 \mathrm{M}$ potassium phosphate, $\mathrm{pH} 7.0$, was titrated with sodium sulfite, which had been standardized against benzoquinone, and no reduction of PAH was observed by monitoring the absorbance at $280 \mathrm{~nm}$. This same PAH sample, then, was fully reduced by dithionite. It may be concluded that sulfite exhibits no appreciable reductive reaction with PAH.

\section{Discussion}

This work shows that a prereduction of PAH is effected immediately prior to the normal catalytic event. When purified PAH is added to a reaction system containing phenylalanine, molecular oxygen, and reduced pterin cofactor, stopped-flow spectrophotometry indicates the presence of a pre-steady reduction of PAH by a stoichiometric amount of $6 \mathrm{MPH}_{4}$, followed by a steady-state catalytic production of tyrosine. It is particularly noteworthy that dithionite can replace $6 \mathrm{MPH}_{4}$ in the reduction step as evidenced by observation of the anticipated tight $1 / 1$ coupling between $6 \mathrm{MPH}_{4}$ oxidation and tyrosine formation exhibited by dithionite-reduced PAH. Thus, addition of only a single electron is necessary for this measure of PAH activation; our data do not preclude the transfer of a second electron from $6 \mathrm{MPH}_{4}$ to the PAH subunit as reported by Marota \& Shiman (1984). The following minimal mechanism is offered as explaining these and our earlier observations:

step 1

$$
\mathrm{PAH}_{\mathrm{ox}}+1 \mathrm{e}^{-} \stackrel{k_{\mathrm{r}}}{\rightarrow} \mathrm{PAH}_{\mathrm{red}} \quad \mathrm{PAH}_{\mathrm{red}} \geq \mathrm{PAH}_{\mathrm{act}}
$$

step 2

$$
\begin{aligned}
& \mathrm{PAH}_{\mathrm{act}}+6 \mathrm{MPH}_{4} \stackrel{K_{\mathrm{s}}^{2}}{=}\left(\mathrm{PAH}_{\mathrm{act}} \cdot 6 \mathrm{MPH}_{4}\right) \stackrel{k_{2}}{\longrightarrow} \\
& +\mathrm{O}_{2}+\mathrm{Phe} \quad \mathrm{Phe} \cdot \mathrm{O}_{2} \\
& \begin{array}{c}
\mathrm{PAH}_{\text {act }}+4 \mathrm{a}-\mathrm{OH}-6 \mathrm{MPH}_{4} \\
+ \text { tyrosine }
\end{array}
\end{aligned}
$$

step 3

$$
4 \mathrm{a}-\mathrm{OH}-6 \mathrm{MPH}_{4} \stackrel{k_{3}}{\longrightarrow} \text { quinonoid-6 } \mathrm{MPH}_{2}+\mathrm{H}_{2} \mathrm{O}
$$

At present, step 1 is accomplished by two different reagents: dithionite under anaerobic conditions or $6 \mathrm{MPH}_{4}$ in the presence of oxygen. In the case of $6 \mathrm{MPH}_{4}$, the detected pterin oxidation product is the quinonoid form. Data from the titration of the enzyme with these two reagents, the product/ cofactor coupling, and the stopped-flow kinetics support the reduction of all the iron in the enzyme in step 1 , i.e., that observed at $g_{\text {eff }} \simeq 4.3$ and $g_{\text {eff }} \simeq 6.7,5.4$. However, only that fraction of hydroxylase that is capable of turnover is included in step 2. Step 3 features the nonenzymatic dehydration of the $4 \mathrm{a}-\mathrm{OH}-6 \mathrm{MPH}_{4}$, a process that is catalyzed by a carbinolamine dehydratase (Lazarus et al., 1983).

The model predicts that a reaction system containing PAH, phenylalanine, and $\mathrm{O}_{2}$ and initiated with $6 \mathrm{MPH}_{4}$ in molar equivalence with enzyme would produce less than one molar equivalent of tyrosine. The actual amount of tyrosine produced per $6 \mathrm{MPH}_{4}$ is dependent upon the value of $k_{\mathrm{r}}$ relative to $K_{\mathrm{S}}{ }^{2}$ and $k_{2}$. For example, if the flux through step 1 is large, most of the available $6 \mathrm{MPH}_{4}$ would be shunted through step 1 before $6 \mathrm{MPH}_{4}$ could react in step 2 to produce tyrosine. The converse would result in a coupling ratio only slightly smaller than unity because the small amount of $\mathrm{PAH}_{\mathrm{act}}$ produced in step 1 would then react in a catalytic cycle (step 2) and turn over most of the $6 \mathrm{MPH}_{4}$ pool to tyrosine. At equivalent $\mathrm{PAH}$ and $6 \mathrm{MPH}_{4}$ concentrations, ca. $40 \%$ of the $\mathrm{PAH}_{0 \mathrm{x}}$ is reductively activated.

The mechanism requires that the reduction of the PAH occurs only once at the beginning of the reaction. During the tyrosine-producing event (step 2), the enzyme functions catalytically and requires no further steps to maintain its activity. The view that the PAH reduction step is a side reaction not related to its catalytic function but serving simply to oxidize cofactor nonproductively may be rebutted by noting that (1) these data mandate the cessation of flux through step 1 after the enzyme is activated since a coupling ratio (tyrosine/ $6 \mathrm{MPH}_{4}$ ) of unity is observed at $6 \mathrm{MPH}_{4}$ levels $>$ PAH (Lazarus et al., 1981; Kaufman, 1971) and (2) our results plus those from pulse-chase experiments demand that unreduced PAH is largely inactive [Table II (Marota \& Shiman, 1984)].

The activation of PAH by prereduction leads to the immediate question as to the locus for the electron furnished by the reducing agent. Since the enzyme contains $1 \mathrm{Fe} /$ subunit, it was essential to characterize the redox state of the iron by examining its spectral properties. The native enzyme displays a composite EPR spectrum, a portion of which has features at effective $g$ values of 6.7 and 5.4 that are similar to, although broader than, features commonly observed in ferric, heme proteins. This spectrum appears to arise from catalytically active ferric iron in a high-spin, $S=5 / 2$, tetragonally distorted state whose integrated intensity closely corresponds to the relative specific activity of the PAH sample. The other portion of the EPR spectrum, with features near $g_{\text {eff }} \simeq 9$ and 4.3 , correlates in intensity with the fraction of catalytically inactive iron. The integrated intensity of the signals in both regions indicates that the iron in PAH is EPR visible. The EPR signals at $g$ values from 5 to 7 disappear when phenylalanine or pterin are added to the anaerobic enzyme. Since anaerobic incubation of the tetrahydropterin cofactor or phenylalanine with PAH does not result in redox chemistry (Lazarus et al., 1981; Kaufman \& Fisher, 1974), the loss of EPR signals cannot furnish information on the prereduction activation (step 1).

Several other non-heme, non-iron-sulfur enzymes possess similar types of EPR signals. Protocatechuate 3,4-dioxygenase exhibits EPR signals with prominent $g \simeq 4.3$ features in the resting enzyme and ones in the region $g_{\text {eff }} \simeq 7-5$ after addition 
of substrate (Que, 1980). Soybean lipoxygenase also exhibits multiple signals in the $g_{\text {eff }} \simeq 8-5$ region after it is treated with $1 \mathrm{~mol}$ of its peroxy product, but the resting enzyme is EPR silent (Slappendel et al., 1982). It is particularly interesting that the PAH case differs from that of these other enzymes in having EPR spectral features at $g_{\text {eff }} \simeq 5-7$ only for the native enzyme, making it clear that the protein itself can provide the environment that gives rise to these signals and that the presence of substrate or activator is not required.

Evidence that $\mathrm{Fe}^{3+}$ is indeed reduced in step 1 was furnished by the observation that the $\mathrm{Fe}^{2+}$ was stoichiometrically trapped by $o$-phenanthroline after reduction by dithionite or $6 \mathrm{MPH}_{4}$ under anaerobic or aerobic conditions, respectively. The initial $\mathrm{Fe}^{3+}$ is not removed. Since the dithionite reduction proceeds quantitatively in the absence of oxygen, the latter's role in the $6 \mathrm{MPH}_{4}$ reduction of the enzyme simply may be to intercept the $\left(\mathrm{Fe}^{2+} \cdot \mathrm{PAH}_{\mathrm{red}}\right)$ species and displace an unfavorable equilibrium:

step 4

$$
\mathrm{Fe}^{3+} \cdot \mathrm{PAH}_{\mathrm{ox}}+6 \mathrm{MPH}_{4} \rightleftharpoons
$$

$$
\left(\mathrm{Fe}^{2+} \cdot \mathrm{PAH}_{\mathrm{red}}\right)+\text { quinonoid-6 } \mathrm{MPH}_{2}
$$

step 5

$$
\left(\mathrm{Fe}^{2+} \cdot \mathrm{PAH}_{\mathrm{red}}\right) \stackrel{\mathrm{O}_{2}}{\longrightarrow} \mathrm{Fe}^{2+} \cdot \mathrm{O}_{2} \cdot \mathrm{PAH}_{\mathrm{red}}
$$

The fact that the $o$-phenanthroline trap of reduced iron is quantitative suggests that both types of iron detected in the EPR spectra can be reduced under these conditions even though that associated with $g_{\text {eff }} \simeq 4.3$ does not contribute to the enzyme's specific activity.

The requirement that molecular oxygen be present for the prereduction of PAH argues in favor of a tertiary complex of enzyme, cofactor, and oxygen being required for electron transfer. This fact suggests that a reduced iron state, Fe(II)-PAH, trapped by oxygen with formation of an ironoxygen intermediate, may precede the formation of the actual hydroxylating species. Enzyme-bound iron-oxygen complexes have been well documented, with cytochrome P-450 (Ullrich \& Duppel, 1975; Orrenius \& Ernster, 1974; White \& Coon, 1980) serving as an especially pertinent example of an enzyme that catalyzes hydroxylation reactions via iron-oxygen chemistry. The fact that the prereduction step may be accomplished anaerobically with dithionite provides an approach to investigate oxygen binding to $\mathrm{Fe}$ (II)-PAH and subsequent intermediates for the hydroxylation reaction.

Registry No. 6MPH 4 , 942-41-6; PAH, 9029-73-6; Fe, 7439-89-6; dithionite, 14844-07-6.

\section{References}

Aasa, R., \& Vänngard, T. (1975) J. Magn. Reson. 19, 308. Ayling, J. E., Pirson, R., Pirson, W., \& Boehm, G. (1973) Anal. Biochem. 51, 80.

Bates, G. W., \& Wernicke, J. (1971) J. Biol. Chem. 246, 3679.

Bates, G. W., \& Schlabach, M. R. (1973) J. Biol. Chem. 248, 3228.

Butler, R. S., \& DeMaine, P. A. D. (1975) Top. Curr. Chem. $58,39$.

Cotton, F. A., \& Wilkinson, G. (1972) Advanced Inorganic Chemistry, p 451, Wiley, New York.

DeMaine, P. A. D. (1980a) in Automatic Systems for the Physical Sciences (Operation Manual for the CRAMS System, Report No. 5), Department of Computer Science,
The Pennsylvania State University, University Park, PA. DeMaine, P. A. D. (1980b) in Automatic Systems for the Physical Sciences (System Manual for the CRAMS System, Report No. 6), Department of Computer Science, The Pennsylvania State University, University Park, PA.

Dixon, M. (1971a) Biochim. Biophys. Acta 226, 241.

Dixon, M. (1971b) Biochim. Biophys. Acta 226, 259.

Fisher, D. B., Kirkwood, R., \& Kaufman, S. (1972) J. Biol. Chem. 247, 5161.

Goodwin, B. L. (1979) in Aromatic Amino Acid Hydroxylases and Mental Disease (Youdim, M. B. H., Ed.) p 40, Wiley, Chichester.

Gottschall, D. W., Dietrich, R. F., Benkovic, S. J., \& Shiman, R. (1982) J. Biol. Chem. 257, 845.

Hapner, K. D., Bradshaw, R. A., Hartzell, C. R., \& Gurd, F. R. N. (1968) J. Biol. Chem. 243, 683.

Kaufman, S. (1971) Adv. Enzymol. Relat. Areas Mol. Biol. 35, 245.

Kaufman, S., \& Fisher, D. B. (1974) in Molecular Mechanisms of Oxygen Activation (Hayaishi, O., Ed.) p 285, Academic Press, New York.

Laemmli, U. K. (1970) Nature (London) 227, 680.

Lazarus, R. A., Dietrich, R. F., Wallick, D. E., \& Benkovic, S. J. (1981) Biochemistry 20, 6834.

Lazarus, R. A., DeBrosse, C. W., \& Benkovic, S. J. (1982a) J. Am. Chem. Soc. 104, 6869.

Lazarus, R. A., DeBrosse, C. W., \& Benkovic, S. J. (1982b) J. Am. Chem. Soc. 104, 6871.

Lazarus, R. A., Benkovic, S. J., \& Kaufman, S. (1983) J. Biol. Chem. 258, 10960-10962.

Marota, J., \& Shiman, R. (1984) Biochemistry (following paper in this issue).

Orrenius, S., \& Ernster, L. (1974) in Molecular Mechanism of Oxygen Activation (Hayaishi, O., Ed.) p 215, Academic Press, New York.

Peterson, G. L. (1977) Anal. Biochem. 83, 346.

Que, L., Jr. (1980) in Structure and Bonding (Dunitz, J. D., Ed.) p 39, Springer-Verlag, New York.

Schilt, A. A. (1969) Analytical Applications of 1,10Phenanthroline and Related Compounds, pp 54-68, Pergamon Press Ltd., Oxford.

Shiman, R. (1980) J. Biol. Chem. 255, 10029.

Shiman, R., \& Gray, D. W. (1980) J. Biol. Chem. 255, 4793.

Shiman, R., \& Jefferson, L. S. (1982) J. Biol. Chem. 257, 839.

Shiman, R., Gray, D. W., \& Pater, A. (1979) J. Biol. Chem. $254,11300$.

Slappendel, S., Veldink, G. A., Vliegenthart, J. F. G., Aasa, R., \& Malmström, B. G. (1980) Biochim. Biophys. Acta 642,30 .

Slappendel, S., Aasa, R., Malmström, B. G., Verhagen, J., Veldink, G. A., \& Vliegenthart, J. F. G. (1982) Biochim. Biophys. Acta 708, 259.

Storm, C. B., Shiman, R., \& Kaufman, S. (1971) J. Org. Chem. 36, 3925.

Ullrich, V., \& Duppel, W. (1975) Enzymes, 3rd Ed. 12, 253.

Van De Bogart, M., \& Beinert, H. (1967) Anal. Biochem. 20 , 325.

Waalkes, T. P., \& Udenfriend, S. (1957) J. Lab. Clin. Med. 50, 733 .

White, R. E., \& Coon, M. J. (1980) Annu. Rev. Biochem. 49, 315.

Williams, C. H., Jr., Arscott, L. D., Matthews, R. G., Thorpe, C., \& Wilkinson, K. D. (1979) Methods Enzymol. 62, 185. 